\title{
Universal iron supplementation: a simple and effective strategy to reduce anaemia among low-income, postpartum women
}

\author{
Amal K Mitra ${ }^{1, *}$ and Amal J Khoury ${ }^{2}$ \\ 'Department of Community Health Sciences, The University of Southern Mississippi, Hattiesburg, MS 39406, \\ USA: ${ }^{2}$ Department of Health Services Administration, East Tennessee State University, TN, USA
}

Submitted 6 October 2010: Accepted 5 May 2011: First published online 23 June 2011

\begin{abstract}
Objective: To reduce prevalence of anaemia in low-income postpartum women. Design: A randomised, non-blind clinical trial was conducted among 959 lowincome, postpartum women in eleven clinics in Mississippi. The clinics were randomised to one of three treatment groups: (i) selective anaemia screening of high-risk women as recommended currently (control); (ii) universal anaemia screening and treatment of anaemic women (group I); and (iii) universal Fe supplementation of $65 \mathrm{mg} / \mathrm{d}$ for two months to all low-income women (group II). All study participants within each clinic received the same treatment. Women were followed up at 6 months after delivery. Hb was measured at baseline and at follow-up. The primary outcome variable was the proportion of women with anaemia after treatment.

Setting: Eleven health clinics in Mississippi.

Subjects: Low-income, postpartum women.

Results: Baseline characteristics of the three study groups were compared using one-way ANOVA and an appropriate post hoc test for continuous variables and the $\chi^{2}$ test for categorical variables. Fifty-two per cent of postpartum women were anaemic $(\mathrm{Hb}<12 \cdot 0 \mathrm{~g} / \mathrm{dl})$ and the rate decreased to $33 \%$ at 6 months after the intervention. Group II women, who received universal Fe supplementation, improved their $\mathrm{Hb}$ status significantly $(P<0 \cdot 001)$ at 6 months postpartum compared with the other groups. Prevalence of anaemia was also significantly lower among group II women $(22 \cdot 5 \%)$ compared with controls (34\%) and group I women ( $43 \% ; P<0 \cdot 001)$.

Conclusions: A universal Fe supplementation strategy was effective in reducing the prevalence of anaemia among low-income postpartum women.
\end{abstract}

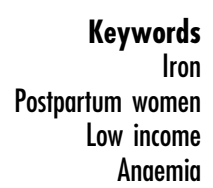

Anaemia affects 1.62 billion people worldwide and one of the primary causes of anaemia is Fe deficiency ${ }^{(1)}$. In the USA, about one in ten women of childbearing age is Fe-deficient, and one in twenty is Fe-deficient and anaemic $^{(2)}$. The prevalence of Fe deficiency is greater among non-Hispanic black and Mexican-American females than non-Hispanic white females ${ }^{(2)}$. Fe requirements are increased during pregnancy due to the expansion of blood volume and growth of the fetus and placenta ${ }^{(3)}$. After delivery, maternal haematological status is expected to return to normal as the expanded red cell mass of pregnancy contracts and Fe returns to body stores; requirements may even be decreased during lactation due to amenorrhoea ${ }^{(3,4)}$.

Considering that women are at low risk of postpartum anaemia, the Centers for Disease Control and Prevention (CDC) recommends anaemia screening at 4 to 6 weeks postpartum only for women who are at 'high risk' of developing postpartum anaemia ${ }^{(5)}$. Risk factors include anaemia continued through the third trimester of pregnancy, excessive blood loss during delivery and multiple birth $^{(5)}$. However, recent investigations suggest that postpartum anaemia is far more common among lowincome women than previously thought ${ }^{(6,7)}$. Among US women in 1988-1994, with household income $<130 \%$ of poverty, the prevalence of anaemia at 0-6 months, 7-12 months and 13-24 months postpartum was 30\%, 20\% and $16 \%$, respectively, compared with $6 \%$ among never pregnant women of childbearing age. In comparison, the prevalence of anaemia was 3 to $8 \%$ among women with income $>130 \%$ of poverty ${ }^{(6)}$. In addition, a high prevalence $(27 \%)$ of anaemia was reported among postpartum women who participated in the Special Supplemental Nutrition Program for Women, Infants, and Children (WIC) in twelve states in the $\mathrm{USA}^{(7)}$. Anaemia rates were even higher among minority women, reaching 48\% among non-Hispanic black women. These studies and others have led some to suggest that anaemia screening 
at 4 to 6 weeks postpartum should not be limited, as it is now, to women at 'high risk' and that other strategies to prevent postpartum anaemia among low-income women deserve consideration ${ }^{(8-10)}$.

Due to the lack of data on Fe supplementation in postpartum women, the present study evaluated the effectiveness of three strategies to prevent Fe deficiency among low-income postpartum women in Mississippi: (i) selective anaemia screening of high-risk women and treatment of anaemic women; (ii) universal anaemia screening and treatment of anaemic women; and (iii) universal Fe supplementation of $65 \mathrm{mg} / \mathrm{d}$ for two months to all lowincome women.

\section{Experimental methods}

\section{Participants}

Women were enrolled in the study from June 2003 to September 2007. Eighteen clinics under the Mississippi Primary Health Care Association (MPHCA) and the Mississippi Department of Health $(\mathrm{MDH})$ were invited to participate in the study through formal letters, telephone calls, and planning committee meetings with staff members of MPHCA and MDH. Eleven of the eighteen clinics agreed to participate.

All postpartum girls and women aged 13 years and older, between 2 and 6 weeks after delivery, and certified for WIC, were eligible for inclusion in the study. The reason for including girls aged 13 years or older was the very high teenage pregnancy rate ${ }^{(11)}$ and a high rate of birth to young teenagers aged 10-14 years in Mississippi ${ }^{(12)}$. A brochure was distributed to eligible women seen at the doctors' office before delivery. Potential participants were identified by site coordinators at a routine clinic visit after delivery. Those with $\mathrm{Hb}<7 \cdot 0 \mathrm{~g} / \mathrm{dl}$ or with sickle cell anaemia were excluded.

The study was approved by the Human Subjects Protection Review Committee of The University of Southern Mississippi, the Institutional Review Board of $\mathrm{MDH}$, and Human Subjects Review Committees at CDC. Women provided informed consent before enrolment. Women who completed the study were given a Walmart gift card worth \$US 20.

\section{Randomisation}

Of the eighteen clinics identified, eleven agreed to participate and seven declined due to lack of adequate manpower to coordinate the study protocol (Fig. 1). The participating clinics were randomised to one of the three treatment protocols: (i) control (selected anaemia screening based on the current recommendations); (ii) group I (universal anaemia screening and Fe treatment); and (iii) group II (universal Fe supplementation), using a random digit chart. All participating women within each clinic were assigned the same treatment protocol.

\section{Site coordinators}

Every clinic administrator selected a site coordinator to enrol and follow up participants. Site coordinators were WIC certifiers, nutritionists or nurse practitioners. Site coordinators enrolled women, recorded weight, height and $\mathrm{Hb}$ test results, dispensed Fe tablets, kept records of women for follow-up, mailed the questionnaire to and maintained liaison with the project director. Body weight was recorded using a bathroom scale with an accuracy of $1 \mathrm{~g}$ and height was measured using a standard mechanical stadiometer with an accuracy of $1 \mathrm{~cm}$. Site coordinators were given a remuneration fee of $\$$ US 10 per patient enrolled.

\section{Interventions}

Control (selective anaemia screening, n 247, four clinics). Each woman at 'high risk' was screened for anaemia according to the CDC (1998) criteria via a finger-puncture blood sample $(500 \mu \mathrm{l})$ using a HemoCue (Quest Diagnostics, Angelholm, Sweden). High risk was defined as anaemia continued through the third trimester of pregnancy, excessive blood loss during delivery and multiple births $^{(5)}$. Anaemia was defined as $\mathrm{Hb}<12 \cdot 0 \mathrm{~g} / \mathrm{dl}^{(10)}$. Anaemic women were given Fe tablets that contained $65 \mathrm{mg}$ of elemental $\mathrm{Fe}$ (325 mg ferrous sulfate) and instructed to take one to three tablets daily for two months according to their $\mathrm{Hb}$ concentration: one tablet daily for $\mathrm{Hb}>10 \cdot 0$ but $<12 \cdot 0 \mathrm{~g} / \mathrm{dl}$; two tablets daily for $\mathrm{Hb}=9 \cdot 0$ to $10 \cdot 0 \mathrm{~g} / \mathrm{dl}$; and three tablets daily for $\mathrm{Hb}=7 \cdot 0$ to $<9 \cdot 0 \mathrm{~g} / \mathrm{dl}^{(13)}$. Supplements were provided free of charge to the women.

Group I (universal anaemia screening, $\mathrm{n}$ 364, four clinics). All participants, regardless of risk of anaemia, were screened for anaemia using finger-puncture blood with analysis via HemoCue. As with the control group, anaemic women were given Fe tablets containing $65 \mathrm{mg}$ of elemental $\mathrm{Fe}$ ( $325 \mathrm{mg}$ ferrous sulfate) and instructed to take one to three such tablets daily (depending on their $\mathrm{Hb}$ concentration) for two months.

Group II (universal supplementation, n 348, three clinics). All women after enrolment were given $\mathrm{Fe}$ tablets containing $65 \mathrm{mg}$ of elemental Fe $(325 \mathrm{mg}$ ferrous sulfate) and instructed to take one such tablet daily for two months. The reasons for choosing this dosage were to: (i) increase adherence with a shorter duration of supplementation; and (ii) balance safety and effectiveness. $\mathrm{Hb}$ concentrations were recorded for all women.

The flowchart shows the treatment protocol for each group (Fig. 1). Women were told that the clinic could be assigned to any of the three treatment groups and were not informed which treatment group the clinic was assigned before they consented to participate in the study. In the event that a clinic dropped out of the study, the treatment group of the dropout clinic was assigned to the new clinic enrolled. 


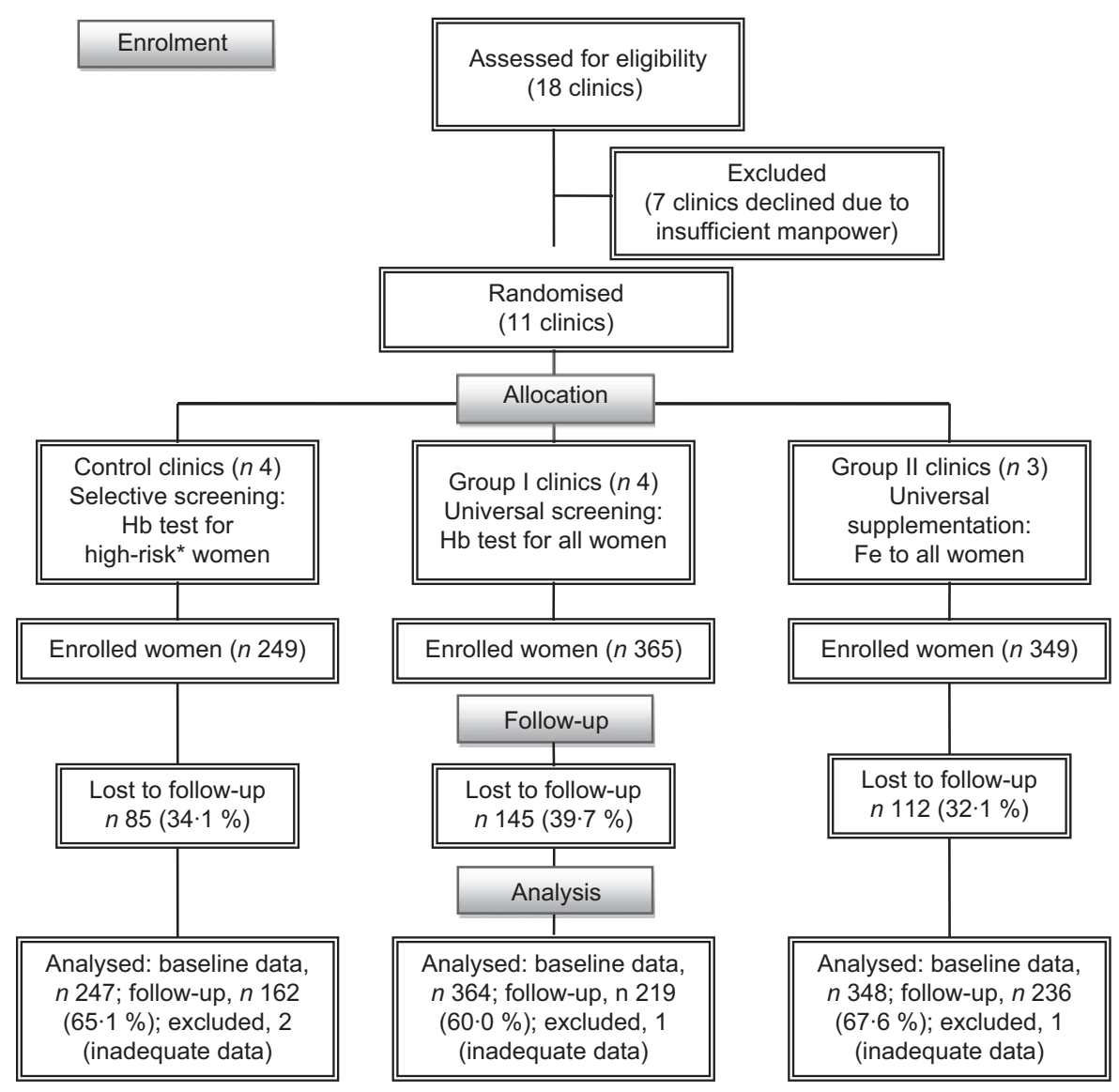

Fig. 1 Distribution of clinics and participating women according to treatment strategy. Each clinic was assigned to one of the three treatment strategies: selective screening (control), universal screening (group I) or universal supplementation (group II). All women in a particular clinic were given the same treatment. *High-risk women included those with: (i) anaemia continued through the third trimester; (ii) excessive blood loss during delivery; (iii) a multiple birth; and (iv) a previous diagnosis of Fe-deficiency anaemia

\section{Study outcomes}

Primary outcome variables included average $\mathrm{Hb}$ concentration and the percentage of women with anaemia at 6 months postpartum.

\section{Questionnaire}

In addition to $\mathrm{Hb}$ tests, participants completed a questionnaire at enrolment. Sociodemographic data included age, race/ethnicity, education, income, family members, smoking history, parity, status of breast-feeding at hospital discharge and a $24 \mathrm{~h}$ (qualitative) dietary recall.

A literature review was conducted to ascertain content validity of the survey questionnaire. Two registered dietitians assessed face validity based on the Dietary Guidelines for Americans $^{(14)}$. The questionnaire was then pilot tested with a sample of fifty low-income postpartum women who did not participate in the study. Open-ended interviews with the pilot-test participants gathered opinion about strengths and weaknesses of the instrument with regard to directions, content, cultural sensitivity, item appropriateness, format, readability and ease of administration. The questionnaire was revised and finalised accordingly.

\section{Follow-up}

All women were asked to come for a follow-up visit at the clinic at 6 months postpartum. Out of 959 women who completed baseline assessment, 617 (64.3\%) came for a follow-up visit. At follow-up, $\mathrm{Hb}$ was measured using finger puncture with analysis by HemoCue, and women were given Fe supplements according to the same dosages if they were still anaemic $(203 / 617,32 \cdot 9 \%)$. Body weight was measured and recorded. Participants also completed the knowledge-attitude part of the questionnaire.

\section{Data quality and monitoring}

A state-wide planning committee, including the study investigators, site coordinators and key staff members of MPHCA and MDH, oversaw the study. The committee worked to enhance communication among collaborating agencies and provided feedback to site coordinators. The committee held two state-wide meetings and communicated by telephone and email throughout the study period. During the first meeting, the site coordinators received hands-on training on $\mathrm{Hb}$ measurement using HemoCue. 
A thorough review of the quality of project implementation was conducted using a combination of methods. (i) The project director conducted internal audits of operations and generated progress reports on a quarterly basis. (ii) A record-keeping system was developed and used to monitor participation in the study. Records were reviewed for completeness. (iii) Several site visits (a minimum of two visits per clinic) were conducted to each participating clinic to monitor progress. (iv) Telephone conference calls were conducted as needed with each of the site coordinators and clinic administrators to assess implementation and support for the study. (v) Biannual meetings of the planning committee were held to oversee implementation.

\section{Compliance}

Considering the fact that compliance to treatment could be an important determinant of outcomes of clinical trials $^{(15)}$, several methods were employed to measure and ensure compliance: (i) after enrolment, the participants were provided information about the importance of Fe supplementation, the effect of Fe deficiency on health, any side-effects of $\mathrm{Fe}$ supplementation and timing of daily oral Fe supplementation; (ii) Fe tablets were given free of charge; (iii) the study team periodically monitored compliance by making telephone calls; (iv) the study team made frequent field visits to clinics to discuss with site coordinators on any potential problems; (v) the study team made household visits to selected houses, as needed; and (vi) the participants were asked to return residual tablets, if any, and bottles at the time of their follow-up visit.

\section{Sample size}

Sample size was estimated based on an estimated baseline prevalence of anaemia of $40 \%$ and a $50 \%$ reduction in the prevalence of anaemia in the intervention group in comparison with the control group, with a two-sided type I error rate of 0.05 and $80 \%$ power $^{(16,17)}$. It was then inflated to reflect an estimate of the variation in the prevalence of postpartum anaemia between clinics based on the variation in the prevalence of postpartum anaemia among low-income women from eight states for which data were available, and the number of women per cluster was 240 .

\section{Statistical methods}

Data were entered and cleaned using the SPSS for Windows statistical software package version 17 (SPSS Inc., Chicago, IL, USA). BMI was computed as weight (in kilograms) divided by the square of height (in metres). Baseline characteristics of women who were followed up and those who were lost to follow-up at 6 months postpartum were compared using Student's $t$ test for continuous variables and the $\chi^{2}$ test of independence for categorical variables. The Mann-Whitney test was used to compare independent means of the two groups for variables that had non-normal distribution.

Baseline characteristics of the three study groups were compared using one-way ANOVA for continuous variables and the $\chi^{2}$ test for categorical variables. Tukey's Honestly Significant Difference test was used to find out statistical difference among the three treatment groups, if applicable. The variables which had nonnormal distributions were compared by the KruskalWallis test among the three groups. Pearson's correlation of $\mathrm{Hb}$ levels was assessed with demographic variables. A probability level of 0.05 or less was considered to be statistically significant.

\section{Results}

Of 963 women enrolled, four were dropped from the analysis because of lack of $\mathrm{Hb}$ values and other baseline information (two controls, one in group I and one in group II; Fig. 1). Demographic characteristics of the four women who were dropped from the analysis were similar to those of the other women. Results presented here represent data from 959 women ( 247 controls, 364 group I and 348 group II) at enrolment and 617 (64.3\%) women who were followed up at 6 months postpartum.

Percentages of women who completed follow-up and were lost to follow-up did not differ statistically among the three study groups $(P=0 \cdot 09)$. The baseline characteristics of women who were lost to follow-up did not differ significantly in terms of age, race/ethnicity, education, income, number of adult family members, smoking status, number of pregnancies, breast-feeding status at hospital discharge, body weight, height, BMI, taking other supplements and consumption of an Fe-rich diet (Table 1). Baseline characteristics of the participants were also not significantly different by treatment group (Table 2).

\section{Hb status}

Hb levels of women in the three treatment groups did not differ significantly $(P=0.583)$ at baseline. Fifty-two per cent (501/959) of the women were anaemic at baseline and were given Fe supplements according to the treatment protocol. However, at 6 months postpartum, the $\mathrm{Hb}$ levels of women in group II (universal supplementation) were significantly higher than those of women in the other two treatment groups (Table 3). The proportion of reduction of anaemia was 20,10 and 27 percentage points among women in the control group, group I and group II, respectively $(P<0 \cdot 001)$. Thirty-three per cent $(203 / 617)$ were still anaemic at 6 months postpartum and were treated accordingly. More than one-third of the study participants had a double burden of anaemia and obesity at enrolment (Table 3). 
Table 1 Baseline characteristics of women who were lost to follow-up at 6 months postpartum in the three treatment groups: low-income postpartum women from eleven health clinics in Mississippi, June 2003 to September 2007

\begin{tabular}{|c|c|c|c|c|c|c|c|}
\hline \multirow[b]{2}{*}{ Characteristic } & \multicolumn{2}{|c|}{ Control ( $n$ 85) } & \multicolumn{2}{|c|}{ Group I ( $n$ 145) } & \multicolumn{2}{|c|}{ Group II ( $n$ 112) } & \multirow[b]{2}{*}{$P$ value } \\
\hline & Mean or $n$ & SD or $\%$ & Mean or $n$ & SD or $\%$ & Mean or $n$ & SD or $\%$ & \\
\hline Age (years) & $23 \cdot 9$ & $6 \cdot 4$ & $23 \cdot 0$ & $4 \cdot 9$ & $22 \cdot 9$ & $4 \cdot 7$ & $0 \cdot 32^{\star}$ \\
\hline Age $<18$ years $(n, \%)$ & 7 & $8 \cdot 5$ & 12 & $8 \cdot 3$ & 9 & $8 \cdot 0$ & $0.76 t$ \\
\hline Race/ethnicity $(n, \%)$ & & & & & & & $0.99+$ \\
\hline White, non-Hispanic & 12 & $14 \cdot 1$ & 13 & $9 \cdot 0$ & 10 & 8.9 & \\
\hline African-American & 70 & $82 \cdot 4$ & 126 & $86 \cdot 9$ & 95 & $84 \cdot 8$ & \\
\hline Other & 3 & $3 \cdot 5$ & 6 & $4 \cdot 1$ & 7 & $6 \cdot 3$ & \\
\hline Education (years) & $11 \cdot 6$ & $2 \cdot 6$ & $12 \cdot 2$ & $2 \cdot 4$ & $11 \cdot 8$ & $2 \cdot 5$ & $0 \cdot 10^{*}$ \\
\hline Monthly household income $(n, \%)$ & & & & & & & $0.23 t$ \\
\hline$<$ SUS 1000 & 53 & $62 \cdot 4$ & 82 & $56 \cdot 5$ & 63 & $56 \cdot 3$ & \\
\hline \$US $1000-2000$ & 26 & $30 \cdot 6$ & 50 & $34 \cdot 5$ & 37 & 33.0 & \\
\hline \$US 2001-3000 & 6 & $7 \cdot 0$ & 10 & $6 \cdot 9$ & 9 & $8 \cdot 0$ & \\
\hline$>\$$ US 3000 & 0 & 0 & 3 & $2 \cdot 1$ & 3 & $2 \cdot 7$ & \\
\hline No. of adults in the family & 1.9 & $1 \cdot 0$ & 1.9 & $1 \cdot 2$ & $1 \cdot 8$ & 0.9 & $0.85 \ddagger$ \\
\hline Smoking status $(n, \%)$ & & & & & & & $0.68 t$ \\
\hline Yes & 14 & $16 \cdot 5$ & 19 & $13 \cdot 1$ & 18 & $16 \cdot 1$ & \\
\hline No & 68 & $80 \cdot 0$ & 120 & $82 \cdot 8$ & 92 & $82 \cdot 1$ & \\
\hline Sometimes & 3 & 3.5 & 6 & $4 \cdot 1$ & 2 & $1 \cdot 8$ & \\
\hline No. of pregnancies & $2 \cdot 6$ & $1 \cdot 8$ & $2 \cdot 3$ & $1 \cdot 4$ & $2 \cdot 3$ & $1 \cdot 3$ & $0 \cdot 33 \ddagger$ \\
\hline Breast-feeding at hospital discharge $(n, \%)$ & 20 & 23.5 & 44 & $30 \cdot 3$ & 38 & 33.9 & $0.33 t$ \\
\hline Body weight (kg) & $81 \cdot 9$ & $20 \cdot 9$ & $79 \cdot 3$ & $22 \cdot 2$ & $78 \cdot 3$ & $28 \cdot 0$ & $0 \cdot 41^{*}$ \\
\hline Height (m) & $1 \cdot 6$ & 0.07 & 1.6 & 0.07 & $1 \cdot 6$ & 0.06 & $0 \cdot 13^{*}$ \\
\hline BMI category $(n, \%)$ & & & & & & & $0.87 \dagger$ \\
\hline$<18.5 \mathrm{~kg} / \mathrm{m}^{2}$ & 2 & $2 \cdot 5$ & 5 & $3 \cdot 4$ & 2 & $1 \cdot 8$ & \\
\hline $18 \cdot 5-24 \cdot 9 \mathrm{~kg} / \mathrm{m}^{2}$ & 23 & $27 \cdot 0$ & 39 & $26 \cdot 9$ & $3 \overline{1}$ & $27 \cdot 7$ & \\
\hline $25 \cdot 0-29 \cdot 9 \mathrm{~kg} / \mathrm{m}^{2}$ & 24 & $28 \cdot 2$ & 43 & $29 \cdot 7$ & 34 & $30 \cdot 4$ & \\
\hline$\geq 30.0 \mathrm{~kg} / \mathrm{m}^{2}$ & 36 & $42 \cdot 3$ & 58 & $40 \cdot 0$ & 45 & $40 \cdot 2$ & \\
\hline \multicolumn{8}{|l|}{ Taking other supplements ( $n$ \%) } \\
\hline Vitamin C & 5 & $5 \cdot 9$ & 8 & $5 \cdot 5$ & 8 & $7 \cdot 1$ & $0 \cdot 75 t$ \\
\hline Vitamin $\mathrm{B}_{12}$ & 2 & $2 \cdot 4$ & 5 & $3 \cdot 4$ & 3 & $2 \cdot 7$ & $0.81 \dagger$ \\
\hline Folic acid & 3 & $3 \cdot 5$ & 4 & $2 \cdot 8$ & 4 & $3 \cdot 6$ & $0 \cdot 86 t$ \\
\hline Consuming Fe-rich food ( $n, \%)$ & 67 & $78 \cdot 8$ & 107 & $73 \cdot 8$ & 82 & $73 \cdot 2$ & $0.64 t$ \\
\hline
\end{tabular}

Data are expressed as mean and standard deviation for continuous variables or number of women and percentage for categorical variables. *One-way ANOVA.

$+\chi^{2}$ test.

$\ddagger$ Kruskal-Wallis test.

\section{Discussion}

In the present study, women in the universal supplementation group improved their $\mathrm{Hb}$ levels significantly more compared with women in other treatment strategies. Anaemia prevalence was also significantly lower $(P<0 \cdot 001)$ among women in the universal supplementation group.

Although the prevalence of postpartum anaemia is high in low-income women in the $\mathrm{USA}^{(7)}$, there is limited evidence for the effectiveness of treatment of postpartum anaemia. However, oral Fe therapy has been used for centuries as a treatment of Fe-deficiency anaemia, and has been established as a treatment for such condition during pregnancy ${ }^{(18)}$.

A review of six randomised controlled trials in postpartum women showed some improvements in haematological indices ( $\mathrm{Hb}$ and haematocrit) when erythropoietin therapy was compared with Fe therapy only and Fe plus folate therapy, but not when compared with placebo ${ }^{(18)}$.

In Germany, postpartum anaemia continued to increase between 1998 and 2003 , from $12 \cdot 2 \%$ to $15 \cdot 0 \%{ }^{(19)}$. Currently, the treatment of postpartum anaemia consists of oral $\mathrm{Fe}$ therapy and blood transfusion ${ }^{(19)}$.
Treatment of anaemia in postpartum women in our study focused on Fe supplementation only. However, the primary cause of anaemia in this population could be multifactorial, including dietary deficiency, excessive haemorrhage, decreased absorption, and deficiency in Fe, vitamin $\mathrm{B}_{12}$ and folic acid. Supplementing folic acid is important for its other role in the prevention of neural tube defects in babies ${ }^{(20)}$. Based on a $24 \mathrm{~h}$ recall, the majority of the women in our study consumed a good amount of Fe-rich food. Also, a small proportion of the women took other supplements. The three treatment groups did not differ in terms of these baseline data on food intake and vitamin supplementation. Our study finding of the effectiveness of the universal Fe supplementation should be assessed on top of the Fe intake through food and intake of other supplements.

Requirements for Fe and Fe metabolism may differ by age group. The inclusion of adolescents is a point of concern, because the results obtained from this group of women may affect the outcome in the overall population. However, the proportion of adolescents in the study was only $8 \%$. A subgroup analysis of these participants showed no differences in the outcome measures of the treatment groups. 
Table 2 Characteristics of women enrolled in the three treatment groups: low-income postpartum women from eleven health clinics in Mississippi, June 2003 to September 2007

\begin{tabular}{|c|c|c|c|c|c|c|c|}
\hline \multirow[b]{2}{*}{ Characteristic } & \multicolumn{2}{|c|}{ Control (n 247) } & \multicolumn{2}{|c|}{ Group I ( $n$ 364) } & \multicolumn{2}{|c|}{ Group II ( $n$ 348) } & \multirow[b]{2}{*}{$P$ value } \\
\hline & Mean or $n$ & SD or $\%$ & Mean or $n$ & SD or $\%$ & Mean or $n$ & SD or $\%$ & \\
\hline Age (years) & $23 \cdot 0$ & $5 \cdot 4$ & $23 \cdot 0$ & $4 \cdot 7$ & $23 \cdot 5$ & $5 \cdot 1$ & $0.59^{*}$ \\
\hline Age $<18$ years $(n, \%)$ & 23 & $9 \cdot 6$ & 25 & $7 \cdot 0$ & 29 & 8.5 & $0.50+$ \\
\hline \multicolumn{7}{|l|}{ Race/ethnicity $(n, \%)$} & $0.72+$ \\
\hline White, non-Hispanic & 23 & $9 \cdot 3$ & 29 & $8 \cdot 0$ & 34 & $9 \cdot 8$ & \\
\hline African-American & 215 & $87 \cdot 0$ & 324 & $89 \cdot 0$ & 298 & $85 \cdot 6$ & \\
\hline Other & 9 & 3.6 & 11 & $3 \cdot 0$ & 16 & $4 \cdot 6$ & \\
\hline Education (years) & $11 \cdot 6$ & $2 \cdot 7$ & $12 \cdot 3$ & $2 \cdot 5$ & $11 \cdot 6$ & $2 \cdot 6$ & $0.96^{*}$ \\
\hline \multicolumn{7}{|l|}{ Monthly household income $(n, \%)$} & $0 \cdot 49+$ \\
\hline$<\$ \cup S 1000$ & 148 & $59 \cdot 9$ & 206 & $58 \cdot 0$ & 188 & $54 \cdot 3$ & \\
\hline \$US 1000-2000 & 82 & $33 \cdot 2$ & 120 & $33 \cdot 0$ & 123 & $35 \cdot 3$ & \\
\hline \$US 2001-3000 & 14 & $5 \cdot 7$ & 25 & $6 \cdot 8$ & 23 & $6 \cdot 6$ & \\
\hline$>\$$ US 3000 & 3 & $1 \cdot 2$ & 8 & $2 \cdot 2$ & 13 & $3 \cdot 7$ & \\
\hline \multirow{2}{*}{\multicolumn{7}{|c|}{ Smoking status $(n, \%)$}} & $0.39 \ddagger$ \\
\hline & & & & & & & $0.73+$ \\
\hline Yes & 28 & $11 \cdot 4$ & 44 & $12 \cdot 1$ & 50 & $14 \cdot 4$ & \\
\hline No & 210 & $85 \cdot 4$ & 304 & 83.5 & 286 & $82 \cdot 2$ & \\
\hline Sometimes & 8 & $3 \cdot 3$ & 16 & $4 \cdot 4$ & 12 & $3 \cdot 4$ & \\
\hline No. of pregnancies & $2 \cdot 2$ & 1.5 & $2 \cdot 3$ & $1 \cdot 4$ & $2 \cdot 2$ & $1 \cdot 3$ & $0.19 \ddagger$ \\
\hline Breast-feeding at hospital discharge $(n, \%)$ & 49 & $20 \cdot 3$ & 100 & $27 \cdot 5$ & 85 & $24 \cdot 6$ & $0 \cdot 13+$ \\
\hline Body weight $(\mathrm{kg})$ & $82 \cdot 5$ & $22 \cdot 0$ & $80 \cdot 4$ & $21 \cdot 2$ & $79 \cdot 4$ & $20 \cdot 3$ & $0 \cdot 19^{*}$ \\
\hline Height $(\mathrm{m})$ & $1 \cdot 6$ & 0.07 & 1.6 & 0.07 & $1 \cdot 6$ & 0.07 & $0.24^{*}$ \\
\hline \multicolumn{7}{|l|}{ BMI category $(n, \%)$} & $0.93+$ \\
\hline$<18.5 \mathrm{~kg} / \mathrm{m}^{2}$ & 3 & $1 \cdot 2$ & 9 & $2 \cdot 5$ & 6 & $1 \cdot 7$ & \\
\hline $18 \cdot 5-24.9 \mathrm{~kg} / \mathrm{m}^{2}$ & 65 & $26 \cdot 3$ & 89 & $24 \cdot 5$ & 87 & $25 \cdot 4$ & \\
\hline $25 \cdot 0-29 \cdot 9 \mathrm{~kg} / \mathrm{m}^{2}$ & 69 & $27 \cdot 9$ & 110 & $30 \cdot 2$ & 102 & $29 \cdot 7$ & \\
\hline$\geq 30 \cdot 0 \mathrm{~kg} / \mathrm{m}^{2}$ & 110 & $44 \cdot 5$ & 156 & $42 \cdot 9$ & 148 & $43 \cdot 1$ & \\
\hline \multicolumn{8}{|l|}{ Taking other supplements $(n, \%)$} \\
\hline Vitamin C & 10 & $4 \cdot 0$ & 13 & $3 \cdot 6$ & 13 & $3 \cdot 8$ & $0.96 t$ \\
\hline Vitamin $\mathrm{B}_{12}$ & 3 & $1 \cdot 2$ & 9 & $2 \cdot 5$ & 10 & $2 \cdot 9$ & $0.39 t$ \\
\hline Folic acid & 6 & $2 \cdot 4$ & 15 & $4 \cdot 1$ & 12 & 3.5 & $0.53 t$ \\
\hline Consuming Fe-rich food ( $n, \%)$ & 450 & $73 \cdot 0$ & 256 & $74 \cdot 8$ & 256 & $74 \cdot 8$ & $0.58 t$ \\
\hline
\end{tabular}

Data are expressed as mean and standard deviation for continuous variables or number of women and percentage for categorical variables.

*One-way ANOVA.

$+\chi^{2}$ test.

$\ddagger$ Kruskal-Wallis test.

Table $3 \mathrm{Hb}$ status and women with anaemia in the three treatment groups: low-income postpartum women from eleven health clinics in Mississippi, June 2003 to September 2007

\begin{tabular}{|c|c|c|c|c|}
\hline Characteristic & Control & Group I & Group II & $P$ value \\
\hline $\mathrm{Hb}$ at enrolment $(\mathrm{g} / \mathrm{dl})$ & & & & 0.58 \\
\hline Mean & $11 \cdot 7$ & $11 \cdot 8$ & $11 \cdot 8$ & \\
\hline SD & $1 \cdot 8$ & $1 \cdot 6$ & $1 \cdot 6$ & \\
\hline$n$ & 247 & 364 & 348 & \\
\hline $\mathrm{Hb}$ at 6 months postpartum $(\mathrm{g} / \mathrm{dl})$ & & & & $<0.001$ \\
\hline Mean & $12 \cdot 2^{\mathrm{a}}$ & $12 \cdot 0^{\mathrm{b}}$ & $12 \cdot 7^{\mathrm{C}}$ & \\
\hline SD & $1 \cdot 3$ & $1 \cdot 4$ & $1 \cdot 4$ & \\
\hline$n$ & 162 & 219 & 236 & \\
\hline Women with anaemia* at enrolment & & & & $0 \cdot 48$ \\
\hline$n / N$ & $134 / 247$ & $194 / 364$ & $173 / 348$ & \\
\hline$\%$ & $54 \cdot 3$ & $53 \cdot 3$ & $49 \cdot 7$ & \\
\hline Women with anaemia at 6 months postpartum & & & & $<0.001$ \\
\hline$n / N$ & $55 / 162$ & $95 / 219$ & $53 / 236$ & \\
\hline$\%$ & $34 \cdot 0$ & $43 \cdot 4$ & $22 \cdot 5$ & \\
\hline \multicolumn{5}{|l|}{ Women with anaemia and obesityt at enrolment } \\
\hline$n / N$ & $96 / 247$ & $143 / 364$ & $125 / 348$ & $0 \cdot 71$ \\
\hline$\%$ & $38 \cdot 9$ & $39 \cdot 3$ & $35 \cdot 9$ & \\
\hline
\end{tabular}

${ }^{\mathrm{a}, \mathrm{b}, \mathrm{c}}$ Significance of the difference by Tukey's Honestly Significant Difference test: a $v$. b, $P=0.254$; a $v$. c, $P=0.002$; b v. c, $P<0.001$.

*Anaemia: $\mathrm{Hb}<12 \cdot 0 \mathrm{~g} / \mathrm{dl}$.

tObesity: $\mathrm{BMI} \geq 30 \cdot 0 \mathrm{~kg} / \mathrm{m}^{2}$.

The side-effects of Fe tablets did not appear to present a barrier to the participants. At follow-up, only $48 / 617$ (8\%) women mentioned gastrointestinal symptoms and only $32 / 617$ (5\%) reported that they had forgotten to take the tablets daily. This contradicts the common belief that women stop taking Fe tablets mainly due to side-effects 
and is consistent with Galloway et al.'s finding that a minority of women taking Fe tables experience side-effects ${ }^{(21)}$.

Compared with low-income women in the USA, a higher proportion of women in our study were anaemic. The majority of participants were African-American and the rates of Fe deficiency and anaemia are higher among African-American women ${ }^{(2,6,7)}$. A great majority $(73 \%)$ of participants also were overweight (30\%) or obese (43\%). This reflects the fact that Mississippi has one of the highest obesity rates in the nation ${ }^{(22)}$. Although Chambers et al. had reported an inverse relationship between serum Fe levels and BMI among Hispanic women in New York City ${ }^{(23)}$, the $\mathrm{Hb}$ status of the present study participants did not differ significantly by category of BMI at enrolment or at follow-up. Among women who were overweight or obese ( $n$ 694), more than $35 \%$ had low $\mathrm{Hb}$ at enrolment and $30 \%$ had low $\mathrm{Hb}$ at follow-up. This double burden of anaemia and obesity can be seen as a nutritional paradox. More studies are needed to combat this double burden of nutritional problems in this low-income population.

The high attrition rate may be a limitation of the present study. However, the missing data should not affect the results because: (i) the attrition rate did not differ significantly among the treatment groups; and (ii) the baseline characteristics of the women who returned $(n$ 617) and those who did not return ( $n$ 342) for a 6-month follow-up visit did not differ significantly in the treatment groups. A similar high attrition rate is not uncommon in previous studies in this low-income population ${ }^{(24)}$.

In conclusion, the present study found that over half of low-income postpartum women were anaemic. A universal Fe supplementation programme, irrespective of $\mathrm{Hb}$ status, was found to be more effective in improving the $\mathrm{Hb}$ levels and prevalence of anaemia among lowincome postpartum women, compared with the other treatment strategies. Policy makers may re-visit the current strategy of selecting high-risk women for anaemia screening and treatment.

\section{Acknowledgements}

This study was funded by the Centers for Disease Control and Prevention, under a cooperative agreement with the Association for Prevention, Teaching and Research (grant number CDC-NCCDPHP-TS-0780). There are no conflicts of interest. A.K.M. (Principal Investigator) developed the project and competed for funding; collected data; supervised project staff and monitored the works in the field; analysed data; and prepared and finalised the manuscript. A.J.K. (Co-investigator) was committed from the inception of the study in data collection, field visits and supervision of the project staff; and helped in review and rewriting of the manuscript. The authors appreciate Mary Cogswell for her contribution as a consultant, Theresa Kittle, Rahil Deepak, Kinjal Desai,
Imran Sunesara and Gina Fiorentini-Wright for their assistance in the study, and Rebecca Holland for reviewing this manuscript.

\section{References}

1. World Health Organization (2008) Worldwide Prevalence of Anaemia, 1993-2005. WHO Global Database on Anaemia. Geneva: WHO; available at http://whqlibdoc.who.int/ publications/2008/9789241596657_eng.pdf

2. Looker AC, Cogswell ME \& Gunter EW (2002) Iron deficiency - United States, 1999-2000. MMWR Morb Mortal Wkly Rep 51, 897-899.

3. Institute of Medicine (2001) Iron. In Dietary Reference Intakes for Vitamin A, Vitamin K, Arsenic, Boron, Chromium, Copper, Iodine, Iron Manganese, Molybdenum, Nickel, Silicon, Vanadium, and Zinc: A Report of the Panel on Micronutrients, pp. 290-393. Washington, DC: National Academy Press.

4. Bothwell TH (1995) Overview and mechanisms of iron regulation. Nutr Rev 53, 237-245.

5. Centers for Disease Control and Prevention (1998) Recommendations to prevent and control iron deficiency in the United States. MMWR Recomm Rep 47, 1-29.

6. Bodnar LM, Cogswell ME \& Scanlon KS (2002) Low income postpartum women are at risk of iron deficiency. $J$ Nutr 132, 2298-2302.

7. Bodnar LM, Scanlon KS, Feedman DS et al. (2001) High prevalence of postpartum anemia among low-income women in the United States. Am J Obstet Gynecol 185, 438-443.

8. Pehrsson PR, Moser-Veillon PB, Sims LS et al. (2001) Postpartum iron status in nonlactating participants and nonparticipants in the Special Supplemental Nutrition Program for Women, Infants, and Children. Am J Clin Nutr 73, 86-92.

9. Bodnar LM, Cogswell ME \& McDonald T (2005) Have we forgotten the significance of postpartum iron deficiency? Am J Obstet Gynecol 193, 36-44.

10. Bodnar LM, Siega-Riz AM, Miller WC et al. (2002) Who should be screened for postpartum anemia? An evaluation of current recommendations. Am J Epidemiol 156, 903-912.

11. Guttmacher Institute (2006) US Teenage Pregnancy Statistics: National and State Trends and Trends by Race and Ethnicity, p. 11. New York: Guttmacher Institute; available at http://www.guttmacher.org/pubs/2006/09/12/ USTPstats.pdf

12. Menacher F, Martin JA, MacDorman MF et al. (2004) Births to 10-14 Year-Old Mothers, 1990-2002: Trends and Health Outcomes. National Vital Statistics Reports, vol. 57, issue 7. Hyattsville, MD: US Department of Health and Human Services; available at http://www.cdc.gov/ nchs/data/nvsr/nvsr53/nvsr53_07.pdf

13. Family Practice Notebook.com (2010) Iron supplementation. http://www.fpnotebook.com/Hemeonc/Pharm/ IrnSplmntn.htm (accessed September 2010).

14. US Department of Health and Human Services \& US Department of Agriculture (2005) Dietary Guidelines for Americans, 2005. http://www.health.gov/dietaryguidelines/ dga2005/document/pdf/DGA2005.pdf (accessed September 2010).

15. Puller T, Kumar S \& Feely M (1989) Compliance in clinical trials. Ann Rheum Dis 48, 871-875.

16. Wittes J (2002) Sample size calculations for randomized controlled trials. Epidemiol Rev 24, 39-53.

17. Cornfield J (1978) Randomization by group: a formal analysis. Am J Epidemiol 108, 100-102. 
18. Dodd JM, Dare MR \& Middleton P (2004) Treatment of women with postpartum iron deficiency anaemia. Cochrane Database Syst Rev issue 4, CD004222.

19. Breymann C, Richter C, Huttner C et al. (2000) Effectiveness of recombinant erythropoietin and iron sucrose vs. iron therapy only in patients with postpartum anaemia and blunted erythropoiesis. Eur J Clin Invest 30, 154-161.

20. Almeida LC \& Cardoso MA (2010) Recommendations for folate intake in women: implications for public health strategies. Cad Saude Publica 26, 2011-2026.

21. Galloway R, Dusch E, Elder L et al. (2002) Women's perceptions of iron deficiency and anemia prevention and control in eight developing countries. Soc Sci Med 55, 529-544.
22. Levi J, Vinter S, St. Laurent R et al. (2008) F as in Fat: How Obesity Policies are Failing in America 2008. Washington, DC: Trust for America's Health, Robert Wood Johnson Foundation; available at http://healthyamericans.org/ reports/obesity2008/Obesity2008Report.pdf

23. Chambers E, Heshka S, Gallagher D et al. (2003) Serum iron and body fat distribution in a multiethnic cohort of adults living in New York City. J Am Diet Assoc 106, 680-684.

24. Khoury AJ, Mitra AK, Hinton A et al. (2002) An innovative video succeeds in addressing barriers to breastfeeding among low-income women. J Hum Lact 18, $125-131$ 